Author: Vu Thi Thao,Philipp Wegelin,Widar von Arx

Article Title: Spatial competition and complementarity in European port regions

Journal Title: Journal of Transport Geography

DOI link to publisher version: https://doi.org/10.1016/j.jtrangeo.2017.04.008

\title{
Are Statutory Passenger Watchdogs Effective in Representing Passenger Interests in Public Transport?
}

\section{Introduction}

In recent years, concerns over effective consumer representation of public transport users have increased considerably. Various forms of users' associations have been set up to safeguard passengers' interests. While some passengers' associations play an influential role, others have a weak position (White, 2010; Schiefelbusch et al., 2009; Jansen and Schiefelbusch, 2009).

The increasing interest in how to improve passenger representation is associated with the privatization and deregulation of public transport. Great Britain, for instance, was the first adopter in Europe to implement regulatory reforms in public transport in the 1980s. It has gone further than any other European state in transferring its public transport services into private management operations governed by market forces, with common practices of competitive tendering (Alexandersson and Hultén, 2006; Lyons and Harman, 2002) and fully deregulated regimes (Matthew et al., 2001). The distinction between the two regimes is that the tendering sector provides essential public transport services that are unprofitable and thus receive a subsidy. The services are provided under regional franchises awarded by local public transport authorities (PTAs) for a specific period and through a competitive bidding process. The tendering regime applies to buses within London and the railway system across the whole country. Almost all bus services in London are operated on gross-cost contracts with quality incentives between Transport for London (TfL) and bus operators (BOs). Within the fully deregulated areas, most local bus services are registered 'commercially' and operate without a subsidy. However, services that are not commercial can also be provided through contracts between PTAs and BOs. Any licensed BO can run the business. Buses in England outside London are operated under this regime (TfL, 2015; CMA, 2016; Matthew 
et al., 2001; Preston, 1991). The British government considered this deregulation process 'in the best of the consumer and the public interest' (Butcher, 2010, p. 6).

Although deregulation in the British bus sector has led to reductions in operating costs and subsidies (Preston and Almutairi, 2013), there is typically only one service provider plying each route and time. Some areas are monopolised by large national operators (Hensher and Wong, 2011), known as the 'big 5'.1 Therefore, passengers have little scope to exercise their power by switching to another service provider when they are unsatisfied with the services provided, although they can use other modes of transport, such as private cars. Nevertheless, an important incentive for operators to improve the passenger experience is absent. Besides, the modal shift from public transport to private cars is generally opposed by policy-makers due to its negative environmental impacts and the congestion it causes (Bonsall, 2000; Cass and Faulconbridge, 2016). Furthermore, in regulated regimes, the relationship between public transport operators (PTOs) and local PTAs can be seen one between 'seller' and 'buyer'. Local PTAs may pursue other interests that differ from those of the end customer, while the operators may adapt their services to PTAs' preferences in order to win a contract (Schiefelbusch, 2005).

In an attempt to safeguard passenger interests, the UK has established statutory, independent passenger watchdogs for public transport. One question is whether, in either regulated or fully deregulated markets, they are an effective mechanism in representing passenger interests? If so, what makes them successful? Applying van de Velde's (1999) strategic-tactical-operational (STO) framework, the current paper seeks to answer these questions by drawing on a case study of two statutory passenger watchdogs in Great Britain, London TravelWatch (LTW) and Transport Focus (TF). The paper focuses on the bus sector in which both the regimes exist. Since similar public transport regimes are also found elsewhere in Europe and worldwide (Schiefelbusch, 2005), the present case study can provide some useful lessons to a wider range of stakeholders. Furthermore, little is known theoretically or empirically about consumer organizations (Guest, 2015). This is particularly true for the public transport sector. There exist a few studies whose focal inquiry is passenger organizations. Therefore, the paper also contributes to the current literature on how passenger watchdog organizations are organized and how they work to protect passenger interests.

1 That is, Go-Ahead, FirstGroup, Stagecoach, National Express and Arriva, who between them account for over $70 \%$ of the bus market in England. 
The paper begins by introducing some elements of public choice theory to clarify the argument in favour of consumer representative bodies in the political process. The paper then briefly discusses the STO framework. It continues by presenting the case selection, methodology and the two passenger watchdogs selected for discussion before turning to the analysis. The paper ends with a discussion of the watchdog role and its relationship with other actors within the STO framework, as well as factors in their success in representing passenger interests.

\section{Theoretical frameworks}

\subsection{Interest groups and the free-rider problem}

Olson (1965) long ago drew our attention to the problem of free-riding behaviour in large and diffuse interest groups. As collective or public goods are characterized by non-excludability, rational and self-interested individuals may take free-ride to enjoy their benefits, whether or not they contribute to the provision of such goods. In addition, in the case of large groups of potential beneficiaries, the benefits may be shared among a huge number of group members, further reducing the incentive to become involved. It is on these grounds that large and diffuse groups such public transport users typically face difficulties in organizing themselves and safeguarding common interests, for example, through lobbying activities in the political decision-making process. In Germany, for instance, there were no organizations that represented users of public transport until the 1980s (Jansen and Schiefelbusch, 2009).

In contrast, small groups with concentrated interests can exert much greater influence on political decision-making, that is, they are more effective in lobbying for special privileges. Excludability is easier to enforce, and often collective action leads to substantial benefits for each group member. Hence, such interest groups are much easier to organize even if group members still act as rational actors maximizing their own utility. As a result, these groups are often over-represented in public debates (Butler, 2012). For instance, the Swiss Association of Public Transport (APT), the umbrella organization of public transport companies, has served as a powerful political lobby for its members since 1889 (APT, 2016).

Particular institutional arrangements can be designed to overcome such imbalances in lobbying power and to correct the corresponding political outcomes. First of all, public administration may step in as an agent for the principal, for example, public transport passengers. However, the selfinterest of actors in the political process, such as legislators, bureaucrats or regulators, as well as 
their exposure to the power of well-organized interest groups, have to be considered in designing such institutions (Butler, 2012). Another measure that is of special interest in the current context consists of establishing independent public agencies outside the administration. It is assumed that such bodies are less exposed to capturing pressure from the political process or the power of interest groups, and therefore they may represent the public interest to a higher degree. In public transport governance, independent regulatory bodies are usually promoted in terms of industry regulation and infrastructure (e.g. Marcucci, 2002; Nash and Matthews, 2002; Ponti and Erba, 2002), but independent bodies may also have their own, possibly hidden agenda that does not coincide with the principal's goals. The main question in the present context is therefore whether passenger watchdogs as independent bodies are indeed superior as an arrangement to represent passengers' interests compared to, for example, PTAs, which are subject to elected governments. In other words, how do passenger watchdogs dissolve the principal-agent problem differently - that is, more in the principal's interest - than other actors?

\subsection{Institutional relationships among key stakeholders in public transport}

As a result of regulatory reforms in recent decades, various organizational models of public transport have been developed and applied in European countries. In a review of the organization of local and regional public transport in Europe, van de Velde (1999) proposes the strategic-tacticaloperational framework, known as the STO framework. This is used widely by transport researchers (Hanson, 2010) for understanding the planning and controlling mechanism in different regulatory regimes, as well as the institutional relationships among the key stakeholders involved.

The STO framework can be seen as a principal-agent chain. At the strategic level, actors such as politicians and their staff formulate general aims for public transport and determine the general instruments that will obtain these goals. Van de Velde (1999) argues that a principal-agent relationship exists between 'the People' (the Public) as an actor and PTAs. The author characterizes this relationship as democratic control, with the assumption that PTAs act on behalf of the public and represent the public interest in defining transport policy and selecting operators. However, as discussed earlier, this assumption is called into question because of the self-interested behaviour of bureaucrats. PTAs may be exposed to the risk of conflicts of interest. Furthermore, it is difficult for 'the People' as an actor to assert control collectively over PTAs because of the free-rider problem in large and diffuse groups. In the present paper, we argue that forming statutory and independent passenger watchdogs can help to reduce these problems. 
At the tactical level, actors such as PTAs decide which instruments to use and how to use them to obtain the aims set by the strategic level. For example, PTAs can use competitive tendering to control PTOs' behaviour. 'The People' as an actor thereby control PTOs indirectly through PTAs. In both authority-initiative and market-initiative regimes, PTAs can play watchdog roles to control operator behaviour, for example, by controlling and monitoring the service performance of PTOs. However, when a PTA also provides public transport services, the watchdog function is usually not carried out by the same authority (van de Velde, 1999). To be credible, this function should be carried out by an independent body. In the analytical section, we will document how LTW and TF watchdogs build credibility while performing their roles.

At the operational level, PTOs ensure that services are delivered effectively and efficiently. Drawing on experiences with tendering in the European Union, Schaaffkamp (2014) claims that many PTAs are, to some extent, dissatisfied with the outcomes of tendered contracts, particularly the decline in patronage and customer satisfaction. The existing contracts seem to lack incentives for operators to focus on passenger needs. Yet PTAs themselves are also a partial reason for these outcomes, as they are usually blamed for concentrating on overall cost reduction rather than passenger needs when designing and awarding tendered contracts.

The need to improve the incorporation of passenger interests into public transport service (Mokonyama and Venter, 2013; Schaaffkamp, 2014; Jansen and Schiefelbusch, 2009) may even be greater under deregulated regimes in which market entry is open. Furthermore, the organizational form of public transport services is made highly complex by the existence of multiple servicedelivery systems. Elgin and Bushnell (1977) argue that system complexity reduces citizens' ability to understand the system and decreases public participation. Who, then, represents passenger interests in public transport? Adopting the STO framework, we attempt to demonstrate that statutory passenger watchdogs in regulated and fully deregulated bus markets with organizational arrangements such as those in Britain are an effective mechanism in representing passenger interests.

\section{Case selection and methods}

Since 1986, bus services in England outside London have been fully deregulated. Any licenced operator can run a new route, even if another operator already provides services on the same route. Operation licences are issued by Regional Traffic Commissioners (VOSA, 2011). In London 
regulation has been retained, but competition has been introduced through tendering for individual routes since 1985 . Only a small proportion of bus services are run commercially under a London Service Permit (TfL, 2015; TfL, n.d.). Transport for London (TfL) is responsible for awarding tendered contracts (VOSA, 2011). Tender evaluation is based on best value for money, particularly in terms of quality and safety.

With its thirty years of experience, the British could provide some interesting insights on the deregulation of public transport, especially as regulatory reforms in public transport are still evolving (van de Velde and Preston, 2013). Additionally, Great Britain has introduced statutory passenger watchdogs as independent bodies to safeguard passenger interests. For these reasons, we selected Britain as our case study.

The central focus of this paper is the role of statutory passenger watchdogs in representing bus passenger interests in different regulatory regimes. We chose TF and LTW for our research inquiries for the following reasons. First, they are prominent and well-established watchdogs that focus mainly on public transport issues. LTW represents the interests of all public transport users regionally, while TF represents the interests of public transport users nationally. Secondly, TF and LTW operate in two distinct bus market regimes, TF in the deregulated bus market outside London, LTW in the regulated bus market within the city.

Table 1. List of organizations interviewed

\begin{tabular}{|c|c|c|c|c|c|c|}
\hline $\begin{array}{l}\text { Form of } \\
\text { regimes }\end{array}$ & $\begin{array}{l}\text { Passenger } \\
\text { Watchdogs }\end{array}$ & PTAs & BOs & $\begin{array}{l}\text { Customer } \\
\text { satisfaction } \\
(\%)(\mathrm{TF}, \\
2016 \mathrm{a})\end{array}$ & $\begin{array}{l}\begin{array}{l}\text { Market } \\
\text { share (\%) } \\
\text { (GoAhead, }\end{array} \\
2016 ; \\
\text { DfT, } \\
\text { 2014b) } \\
\end{array}$ & $\begin{array}{l}\text { Rank } \\
\text { ridership } \\
\text { per } \\
\text { capita } \\
\text { (DfT, } \\
2016) \\
\end{array}$ \\
\hline \multirow[t]{2}{*}{$\begin{array}{l}\text { Regulated } \\
\text { regime in } \\
\text { London }\end{array}$} & \multirow[t]{2}{*}{ LTW } & \multirow{2}{*}{$\begin{array}{l}\text { Transport for } \\
\text { London (TfL) }\end{array}$} & $\begin{array}{l}\text { Stagecoach } \\
\text { London }\end{array}$ & - & 15 & - \\
\hline & & & Go-Ahead $(*)$ & - & 24 & - \\
\hline \multirow{5}{*}{$\begin{array}{l}\text { Fully } \\
\text { deregulated } \\
\text { regime in } \\
\text { England } \\
\text { outside } \\
\text { London }\end{array}$} & & & $\begin{array}{l}\text { Brighton \& Hove } \\
\text { Bus Company }\end{array}$ & 90 & 94.1 & 1 \\
\hline & & $\begin{array}{l}\text { Oxfordshire } \\
\text { County } \\
\text { Council }\end{array}$ & $\begin{array}{l}\text { Oxford Bus } \\
\text { Company }\end{array}$ & 91 & 46.1 & 21 \\
\hline & & & $\begin{array}{l}\text { Stagecoach Group } \\
(*)\end{array}$ & 86 & 23 & - \\
\hline & & & $\begin{array}{l}\text { National Express } \\
\text { West Midlands }\end{array}$ & 85 & 75.5 & 5 \\
\hline & & & First Midlands & & & \\
\hline
\end{tabular}




\begin{tabular}{|c|c|c|c|}
\hline - $\quad$ First Potteries & 86 & 14.8 & 67 \\
\hline $\begin{array}{ll}\text { - First } \\
\quad \text { Worcestershire }\end{array}$ & - & 36 & 70 \\
\hline - First Leicester & - & 45 & 14 \\
\hline
\end{tabular}

(*) The interviewee has worked across the whole group. Hence, the interview is used for the situation both within and outside London.

The analysis is based primarily on semi-structured interviews with managers of TF and LTW as well as of PTAs, and BOs within and outside London (see Table 1). The interviews were conducted in October 2015 and January 2017 with the aim of understanding passenger watchdogs' roles, activities and cooperation and their relationships with their key stakeholders. In addition, public documentation such as (triennial) reviews and reports were used to complement the interview data. All interviewees' names are pseudonyms.

The BOs interviewed belong to four out of the five biggest operators in England and account for about $50 \%$ of bus services within and outside London (DfT, 2014a). As can be seen in Table 1, most of the interviewed BOs dominate the local bus market in which they operate. Among these BOs, Go-Ahead generally performs better on most of TF's bus passenger survey indicators measuring customer satisfaction (89\%), followed by Stagecoach, National Express and FirstGroup. Oxford Bus Company and Brighton \& Hove Bus Company are part of the Go-Ahead group (TF, 2016a) and have high market shares and bus usage. National Express West Midlands is a part of the National Express group and enjoys a similar market position to the Brighton \& Hove Bus Company. First Midlands is a subsidiary of the FirstGroup and operates in Leicester, Staffordshire and Worcestershire. The latter two areas are among the regions with the lowest level of bus ridership per capita (DfT, 2016).

We acknowledge some limitations in our findings due to the small sample size. Nevertheless, our two atypical cases (i.e. they are considered much more successful in promoting transport user interests than passenger watchdogs in the rest of Europe (Schiefelbusch et al., 2009)) provide a rich understanding of such a complex issue (c.f. Flyvberg, 2006) in the representation and protection of passenger interests in both regulated and deregulated regimes.

\section{Transport Focus and London TravelWatch}

4.1. History, structure and resources 
TF was founded in 2006, though its origins can be traced back to the 1947 Transport Act. This was at the time of the nationalization of the public transport network, under which the Central Transport Consultative Committee and a network of regional Transport Users' Consultative Committees were set up to represent the public interest (Transport Act, 1947). TF came closer to its current form under the 2005 Railways Act, which established a new Rail Passengers' Council as a single national organization (White Paper, 2004). In 2006, it widened its roles to represent rail passengers in England, Scotland and Wales, bus and tram passengers, as well as passengers on scheduled domestic coach services in England outside London (DfT, 2015). In 2015, it further extended its roles to represent users of the Strategic Roads Network in England (TF, n.d.). TF is funded by the Department for Transport (DfT), operates as a non-executive, non-departmental public body and works under a management framework agreement with DfT. The aim of this arrangement as an arm's-length body is to ensure that TF undertakes statutory functions independently from DfT (DfT, 2014c). TF is a relatively small organization with about fifty employees, its research unit being its biggest unit. TF has gone through major budget cutbacks in recent years, its current annual budget being around $£ 5$ million (DfT, 2015).

LTW is an independent transport user's organization set up by Parliament to represent the voice of London's travelling public. Like TF, its origins date back to the 1947 Transport Act, when the London Transport Users Consultative Committee was established to watch over passenger interests in London. Though its duty has remained the same since then, its names have changed several times in accordance with the extension of its geographical and modal responsibility. On the formation of the Greater London Authority in 2000, the passenger representative body in London was taken over by the London Assembly and adopted LTW as its operating name in 2005/2006 (London Assembly, 2010).

LTW has a similar organizational form to TF. It is funded by and operated under an agreement framework with the London Assembly. LTW's chair and board members are appointed by the London Assembly but cannot be represented by the Assembly, the Mayor or TfL. In recent years, the watchdog has gone through a major organizational restructuring involving budget cutbacks. LTW currently has fewer than twenty staff and an annual budget of around $£ 1$ million (LTW, 2015a; 2015b).

\subsection{Main activities in representing bus passenger interests}




\subsubsection{Research}

As TF and LTW are non-executive bodies, they do not have any formal executive power. To safeguard passenger interests, they construct their arguments from research-based evidence into passengers' experiences and expectations. Hence, research is central to the passenger watchdog's work, particularly the national surveys of bus passengers2 for which TF took over responsibility from DfT in 2010. BOs are randomly selected3 across local transport authorities and BOs' subsidiaries to ensure a representative sample. The bus passenger survey is conducted yearly with a sample size of around 50,000 passengers. It is roughly equally funded by TF, BOs and PTAs (TF, 2016a). TF does not carry out the bus passenger survey by itself but contracts research agencies. A whole range of metrics such as punctuality, reliability, value for money, fares and ticketing are used to measure the levels of customer satisfaction for different BOs. The surveys benchmark operators' performances against each other and show trends over time. The national bus passenger surveys are considered a powerful instrument and are used by government and the industry (Wright et al., 2015; TF, 2016a). TF also carries out research into specific issues, for example, 'Bus Passengers have their Say' and 'Bus Service Changes' (TF, 2016b).

LTW is less involved in large-scale user surveys, though it also undertakes research to monitor operators' performance from the passenger's perspective for bus and other modes of transport in London. It produces quarterly monitoring reports (LTW, 2015b). Based on these research findings, LTW conducts further research into the major concerns of passengers, such as bus passengers' priorities for improvements, public transport affordability and value for money. The combination of monitoring operators' performance and more focused research helps the two watchdogs understand passenger needs and supports the case for improvements in the interests of passengers.

\subsubsection{Handling complaints}

LTW only deals with complaints that cannot be solved between passengers and BOs. It has a casework team to handle bus-user complaints together with complaints regarding all other modes of

\footnotetext{
$2 \mathrm{TF}$ and LTW play a considerable role in representing rail passengers as well, especially through the national rail passenger survey conducted by TF.

3 Since bus operators can pay TF to be part of the survey, selection is not purely random (Passenger Focus, 2012).
} 
travel (except rail) in London. TF has no responsibility for handling bus passenger complaints outside London. This function is undertaken by Bus Users UK.4

\subsubsection{Consultation}

Other remits of LTW include statutory consultancy in respect of changes to transport infrastructure and services. For instance, TfL is required to consult with LTW regarding proposed changes to bus services and to take account of LTW's views in reviewing bus tender bids (TfL, 2015). Similarly, TfL has a statutory obligation to consult LTW before making changes to the transport network. BOs have to take part in meetings and seminars organised by LTW, but they have no obligation to implement what LTW recommends (LTW, 2015a). Therefore, LTW is in continuous dialogue with PTAs and BOs. In addition, LTW has regular meetings with important politicians from relevant departments and committees, as well as with London's members of parliament. Although TF has no statutory consultancy, it proactively engages in dialogues with BOs and PTAs, as discussed below.

\section{Findings}

In this section, we document the results gathered from interviews with LTW, TF, BOs and PTAs. We mainly focus on service quality improvements, as these appear to be the most significant outcomes of passenger watchdogs' activities in representing bus passenger interests. We also attempt to provide explanations for how passenger watchdogs may be able to deliver these benefits by using the STO framework, as well as by drawing upon elements of public choice theory namely self-interested behaviour and the free-rider problem - to scrutinize the functions and relationships of passenger watchdogs with key stakeholders such as BOs and PTAs.

\subsection{Improving service quality}

\subsubsection{Proposing concrete changes to services}

Through its work, LTW can leverage a wide range of immediate issues such as fares, ticketing, value for money, punctuality, accessibility and visibility, etc. For example, based on its research, LTW found that a lot of passengers are concerned with fare levels and the various offers for different usage intensities. LTW therefore recommended that operators spread the cost of an annual season ticket and advised TfL to provide better information about the benefits of this ticket and

4 A non-profit organization whose work aims to represent bus-users in England outside London, Scotland and Wales. 
about the Oyster Card (an electronic ticket card) ticketing process. The operators took these recommendations into consideration by improving awareness of seasonal ticket benefits, installing ticket machines that sell zone tickets and improving signage around Oyster validators. TfL improved information about peak and off-peak pricing.

In another example, LTW noticed (through complaint case handling) an increasing number of passengers with mobility impairments, such as wheelchair users and parents with buggies, and the corresponding need to improve the accessibility of buses. Thus LTW actively campaigned to prioritize the provision of an accessible bus network with low-floor buses and accessible bus stops. Since 2009, the number of accessible bus stops is included in the quarterly performance monitoring reports. Hence, by encouraging BOs and PTAs to take action in improving accessibility, the number of accessible bus stops in London has increased in recent years.

Similarly, TF's work has also contributed to the improvement of bus services. For example, based on its 'Bus Passenger Priorities for Improvement' research, TF found that bus passengers give a high priority to the availability of tickets that entitle passengers to travel on bus services with more than one operator. Therefore, the watchdog actively supported multi-operator ticketing to increase the convenience of bus journeys for passengers and value for money. It also assisted DfT in planning and implementing the multi-operator bus ticketing scheme. TF helped to bring together different companies and local authorities in realization of this ticketing scheme. Since the beginning of 2016, the 'big 5' BO groups have offered multi-operator ticketing in all nine major cities in England outside London. Passengers who live on the borders of different local authority areas are benefit especially from this smart ticketing.

In West Midlands, First provides the service during the day and another small bus company runs the evening service [...] Transport Focus was able to mediate an agreement of a ticketing solution between the two operators in those circumstances where we couldn't do it directly. (Gary Y., First Midlands)

\subsubsection{Establishing virtual performance competition among BOs}

TF mainly works with BOs in the national bus passenger survey, which benchmarks operators' service performance against their peers across England outside London. This makes the survey a virtual competition among BOs. Since the survey findings are made available to the public, BOs come under pressure not only from PTAs and their peers, but also from their customers to improve 
their service performances. Through the monitoring performances, TF can enhance transparency regarding service-quality levels among different BOs. This transparency of information could restraint the self-interested behaviour of BOs, who may seek to pursue solely commercial interests, for example, setting a much higher fare.

Yes, the result shows a high level of satisfaction amongst their passengers in that area, which is good to see. Of course, it takes a lot of pressure off. (Gary Y., First Midlands)

For example, the First operator from one side of the town and Stagecoach on the other. The Stagecoach seemed so much better for value for money, their rating is much better. So that actually encouraged the First to drop their prices. So they have done that there and for Great Britain as well. (Albert S., TF)

BOs can access the survey findings to investigate further the reasons for low performance scores and then seek alternative measures to increase service quality:

We value them [the national bus passenger surveys]: they provide information on different categories, and we can use them to change what is not so good. For example, we learned that the speed of the journeys is not so good, so then we used their information and thought maybe we should use buses with two doors. Because when it is one door, people wait for one to get off, it takes a lot more time. It's much faster with two doors, and we will introduce them next year. Also, driver attitude information can be fitted in the training courses. (Parker G., Brighton \& Hove Bus Company)

Although some BOs questioned the reliability of customer satisfaction indicators5 they do value the information about customer satisfaction levels in TF's bus passenger survey. For example, they can use it to prove that they have tried to push up service quality. As soon as the survey's results are released, those BOs that reach high customer satisfaction levels eagerly communicate this news in their own publicity. An assessment of good performance is considered a valuable award, while a supposed bad performance may create pressure on BOs to invest extra efforts in improving services. This indicates that the national bus passenger survey is 'widely discussed and appreciated by the industry people' (Gerald F., National Express West Midlands).

\footnotetext{
${ }_{5}$ Customer satisfaction is likely influenced by customer expectations that differ greatly among local authority areas. For example, customer satisfaction with bus services in London is lower than in the rest of the country: even though the service quality is much higher, so are the expectations of Londoners.
} 
Within the regulated regime in London, LTW indirectly contributes to performance competition among BOs by pressing TfL. The watchdog produces quarterly monitoring reports of all contracted bus routes awarded by TfL, which compare actual performance per route with the minimum service standard agreed between BOs and TfL. For those consistently poor performing routes, LTW investigates further to identify the causes and propose improvement measures. It then asks TfL to take actions to implement these recommendations. If the causes arose from TfL's side, for example, being a matter of policies or infrastructure, TfL is required to solve the problems. If the causes arose from the BOs side, TfL asks poor performing BOs to take measures to increase service quality. In any case, TfL must respond to LTW's recommendations. By doing so, LTW can control selfinterested behaviour on the part of TfL, which could attempt to pursue its own political interests, rather than taking the views of passenger and of the whole bus industry into consideration.

We $[\mathrm{TfL}]$ do take into account everything they [LTW] recommend. We might not do everything they recommend, but we have to make justification about why we take an alternative course of action. [...] We might respond to some of it in writings but also with a long discussion based on the recommendations. That is really how they hold us to account. (Bradley P., TfL)

It can be seen that TF and LTW play an important role in improving service quality. Yet, their ability to influence matters and their ways of doing so vary, as does the degree of actual effect they have, which can depend on their geographical and administrative area of responsibility, their legal status and the distinctive characteristics of bus markets across the country. In addition, service quality improvements do not come from LTW's and TF's efforts alone. Public transport problems are usually complicated issues with a lot of factors and actors involved in leveraging changes. Cooperation among key actors is required, and the passenger watchdog is just one of them.

\subsection{Platform for cooperation and nurturing relationships with key stakeholders}

In this section, we document in detail how the watchdogs influence these actors in taking bus users' interests into account and how they cope with the free-rider problem. As mentioned above, TF mainly works with BOs, whereas LTW mostly interacts with the local PTA (TfL). The reason why TF and LTW concentrate in building relationships with BOs and the local PTA respectively lies in the distinctive characteristics of the bus market both within and outside London. In the deregulated market outside London, all services such as fares, routes, timetables and types of vehicle are decided by private operators, which are apparently TF's most important stakeholder. Therefore, TF 
tends to focus more on influencing BOs in safeguarding customer interests. Whilst the bus market inside London is regulated by TfL, LTW seeks to leverage TfL.

Outside London, we operate the services ourselves. So it's not a transport body between us and the customer. In that respect, Transport Focus would take a bigger role than they do in terms of their direct relationships with the operator than inside London. (Bruce H., Go-Ahead)

Buses are contracted by Transport for London. Certainly, through Transport for London we have a high level of involvement, in all the activities of Transport for London (Bradley P., LTW)

My personal view is that they [LTW] are relatively anonymous to the bus operator. We have very little to do with them on a day to day basis [...]. They don't tend to talk to us on particular areas. (Curtis W., Stagecoach London)

It should be mentioned, however, that TF does consider local PTAs to be key stakeholders and that LTW does have contacts with BOs. Moreover, the watchdogs do work with these actors on certain issues: for example, LTW worked together with TfL and BOs in an investigation into safety issues. However, as small organizations, TF and LTW cannot spend many of their resources in cooperating with these actors. To certain extent, the interaction between TF and local PTAs, and between LTW and BOs, is quite limited. As a consequence, TF tends not to be close enough to understand local concerns or to propose potential improvements. This could be a drawback for a national passenger watchdog. For BOs in London, this is not their concern because they have a tight relationship with TfL, to which they are accountable.

We do not really have contacts with them $[\mathrm{TF}]$. When the government reduced the amount of money, so they cut two third of their staff, and they concentrate more or less on entirely on this service [...] I feel it is less accessible. (John D., Oxford City Council)

Although TF and LTW tend to emphasize different actors in representing bus users' interests, the watchdogs pursue similar strategies in influencing BOs and PTAs. They both realize that to champion passenger interests, establishing credibility with these stakeholders is vital. In doing so, they build networks and contacts at stakeholder meetings and conferences. Through these exchanges, they can openly express their opinions and discuss issues directly with senior staff from PTAs and BOs. The meetings also help in the search for additional funds and to improve the coordination of research activities. 
$[\ldots]$ the way that they $[\mathrm{TF}]$ do this is to organize a series of workshops or seminars and invite you [BO] to come along. [...]. It is not compulsory but [...] it's good to be seen. And often the traffic commissioner goes to these seminars. It is very unofficial, but it is. (Alan B., Oxford Bus Company)

Occasionally our research team meet with theirs to make sure [...] they won't duplicate anything of what we were doing. (David J., LTW)

At those senior meetings, the watchdog's leadership will express what they think is going well, areas of concern and we will come back to those respondents and gave our position on those. (Bradley P., TfL)

With a set of results from the national passenger surveys, passenger managers from TF visit BOs across Great Britain to discuss their performance and jointly develop action plans to improve service quality. The passenger manager team will revisit these operators after six months or a year with another set of results to see if service quality has improved or not. TF has built up a close relationship with BOs through these sorts of workshops.

\subsection{Building credibility}

Although LTW and TF can publicly criticize PTAs and BOs for "failed" projects and/or bad service quality, however, they prefer to follow a strategy of accommodation in working with these stakeholders. On the one hand, they seek to collaborate with the industry and avoid striking an aggressive stance. On the other hand, the watchdogs see themselves as a public body assisting central and local governments. They therefore help PTAs set standards, as well as monitor and enforce compliance with tendered contract conditions.

They $[\mathrm{TF}]$ tend trying being non-confrontational. I sometimes think they [are] trying to keep everybody on their side. (Alison J., Stagecoach Group)

They [TF] will never come and say, 'You need to do X, Y, and Z'. They will never criticise operators. [...] Their focus is on positive promotion and willing people to improve on a voluntary basis. (Alan B., Oxford Bus Company)

A challenge is also about maintaining good relationships with either the people providing the service or those influencing it, funding it. (Davis J., LTW) 
LTW and TF adopt a strategy of accommodation for two main reasons. First, they have little statutory power to influence PTAs and BOs. Secondly, they depend on PTAs and BOs for funding. TF receives one third of its budget for the national bus passenger survey from BOs by ordering additional reports or including BOs in the sample when the latter are randomly excluded from the survey. LTW receives additional funding from TfL through commissioned work. This dependence on PTAs and BOs might challenge the very nature of LTW's and TF's watchdog role, affecting perceptions of their independence and their ability to represent passengers' interests. LTW and TF's behaviour might be also influenced by their own self-interest.

So if they [TF] do not select our subsidiaries to be surveyed, we do it anyway. We pay TF to make sure that each of our companies is done at least once a year. So we have an overview how is our company doing at least once a year. [...]. It is not cheap, but it is useful information, and it is useful market research. (Alan B., Oxford Bus Company)

Research-based evidence, together with the power of the media, provides these passenger watchdogs with a degree of coercive power that helps them secure the cooperation of BOs and PTAs. Both TF and LTW pay great attention to the dissemination of research results. They have their own press offices or communications delegates and use multiple channels of communication such as social media, blogs and newsletters. The watchdogs also publish all research results on their own website and put them in the public domain. The mass media generally focus on bad operators and bad stories, which may reach the ears of the government through members of parliament. Consequently, PTAs and BOs have to cope with this sort of pressure from the mass media by increasing service quality. Another contribution of these outreach activities is to increase the importance of public bus services nationally.

You know, for us, we take that very seriously if they publicly criticised us in press. So we work closely to make sure that we don't really get to that point. (Bradley P., TfL)

If you ignore the research and continue on the bottom. [...] You get named and shamed. (Alan B., Oxford Bus Company)

Like other large interest groups, the biggest challenge that the passenger watchdogs face is to keep themselves relevant to the public. A lack of public involvement could weaken the watchdogs' influence. To cope with such a free-rider problem, TF and LTW try to make themselves visible and easily accessible to a wider public. For instance, LTW opens their policy and board meetings, as 
well as other relevant meetings, to the public. Those who cannot attend physically can follow the meeting's progress on Twitter. Questions can be sent by email or Twitter before and during the meeting. TF is piloting an online version of the national passenger survey to try and counter a falling response rate.

PTAs and BOs describe passenger watchdogs as their 'critical friends'. The watchdogs give these stakeholders opportunities to express their points of view and the rationale for their decisions. However, in cases when the parties cannot reach a satisfactory agreement on disputed matters, the watchdogs may propose sanctions on these stakeholders, for example, criticize them in public. Likewise, for those BOs who paid to be surveyed, the performance results will be placed in the public domain. However, BOs and TF might raise issue on some of the findings, especially when it comes to low customer satisfaction scores that BOs do not wish to be published. TF then allows a certain amount of time to discuss the findings with the BOs, and they can usually come up with a joint conclusion. If they are unable to come to an agreement, TF will still place the findings in the public domain. By doing so, the watchdog seeks to maintain its independence and transparency, even while following a strategy of accommodation.

We also have to maintain our independence, and there might be an occasion where we take the passenger's point of view and the [London] Assembly takes the public interest. It has happened occasionally in the past that we have a different position than the Assembly because we come from the passenger's point of view, and they come from another. (Davis J., LTW)

\section{Discussion and conclusion}

This paper has attempted to explore the role of passenger watchdogs in representing bus passengers' interests and to examine how they are able to achieve this goal in different market regimes. Fig. 1 describes LTW's functions and relationship with TfL and BOs in the regulated regime in London. In this model, the watchdog can be seen as an agent of the transport authority because it is funded by and operated under an agreement with the London Assembly. Yet the watchdog also represents, to some extent, 'the People' as an actor, since it seeks to safeguard the public interest, that is, passenger interests.

The relationship between LTW, TfL and the BOs can be described as a quasi-principal-agent relationship. The passenger watchdog does not give any mandate to $\mathrm{TfL}$ and the BOs, but it still can influence them to follow the conditions set out in tendered contracts and to take its 
recommendations into consideration. LTW could do this by regularly monitoring BOs' performances, conducting research and statutory consultation. However, it has a much closer relationship with the local PTA (TfL) than with BOs. The watchdog indirectly influences BOs through the regulator, TfL. Studying constitutional watchdogs in the UK, Oonagh and Winetrobe (2008) also claim that watchdog experts are needed to act impartially because of the lack of trust in elected representatives making all decisions. Moreover, the fact that the passenger watchdog is brought into this relationship can be explained by Amaral's empirical findings (2008) that, under regulatory reforms in the European Union, local PTAs often have limited expertise and capacity in awarding contracts and controlling the compliance of PTOs with their contract's service standards. Therefore, the passenger watchdog can be seen as a meaningful mechanism minimizing the principal-agent problem in contracting out public transport services.

Fig. 1. The passenger watchdog in the regulated bus regime (adapted from van de Velde, 1999*)

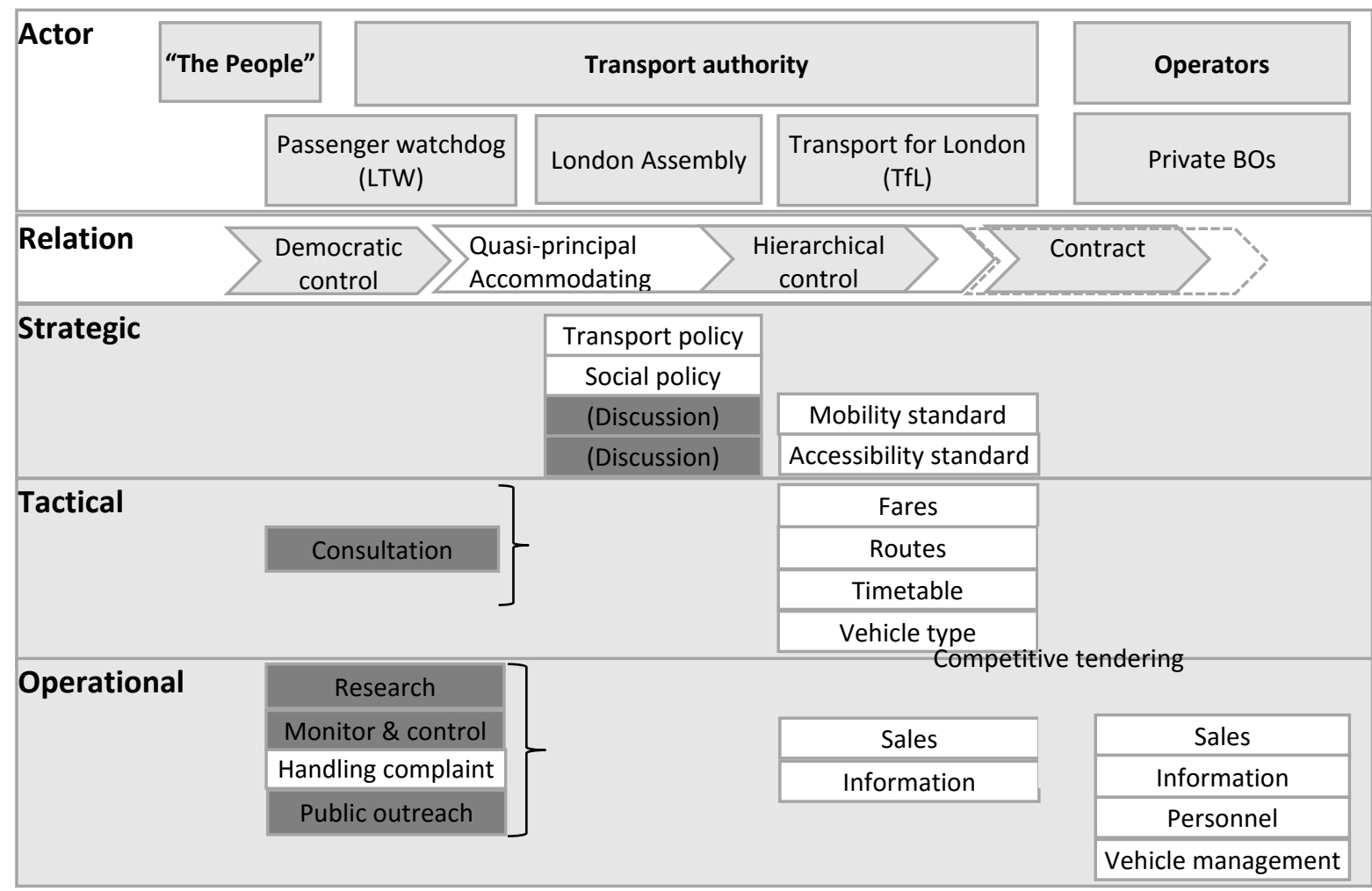

(*) The first row indicates which actors are involved in the organizational form. The second row describes the control relationship between the actors involved. The $3^{\text {rd }}, 4^{\text {th }}$ and $5^{\text {th }}$ rows indicate which actors are responsible for which decisions. The decisions are indicated under the responsible actor. A white block indicates that the actor under which the block falls has the main or sole responsibility for that decision. A shaded block indicates that other actors can also carry out that task. For example, besides passenger watchdogs, research can also be done by PTAs. Text between brackets and in shaded blocks indicates the types of influence that each actor enjoys. Vertical text shows the instrument or selection mechanism used to 
put the relationship in place (van Velde, 1999: $p$. 153-154). The curly braces indicate that the tasks for which the passenger watchdog is responsible correspond to several of TfL's and BOs' tasks. For instance, LTW advises TfL on fares, routes and timetables. The dotted line means that the relationship is rather loose.

The relationships of LTW with TfL and BOs can also be characterized as accommodating, as the watchdog seeks compromise solutions in its relationships with these stakeholders by following a strategy of accommodation. It therefore collaborates with TfL and avoids aggressive stances. It also sees itself as a public body assisting the central and local governments.

While not being present at the strategic level, LTW plays some roles at the tactical level. Through its consultation activity, it suggests that TfL undertakes concrete changes to services, such as fares, routes and timetable. However, the watchdog mainly operates at the operational level, controlling and monitoring TfL's and BOs' performance in the provision of bus services, such as points of sale, communication of information (e.g. ticket benefits and fares) to bus users and staff behaviour. Consultation as well as monitoring and controlling are closely linked to their research activities. The watchdog is also responsible for handling complaints when these cannot be solved directly between a customer and a BO. Another important task which LTW pursues is public outreach to engage with a wider public, disseminating research results and passenger-relevant information in both traditional and social media channels. It also encourages the public to participate into its activities physically and virtually, in its attempts to mitigate the free-rider problem. At the same time, these outreach activities contribute to increasing the importance of public bus services nationally.

Fig. 2 shows the relationships and functions of TF with PTAs and BOs in the deregulated regime outside London. In this model, TF can be seen as an agent of the regulatory authority because it is funded by and operates under an agreement framework with DfT. The relationship of TF with local PTAs and BOs can be characterized as accommodating. TF appears to be more active than LTW in building this kind of relationship with PTAs and BOs because TF has no statutory consultation roles in the deregulated market. Local PTAs and BOs have no obligations to take TF's recommendations into consideration or participate in its meetings and workshops. Moreover, in the deregulated market outside London, BOs are responsible for the design of their bus services from the strategic to the operational level. Thus, unlike LTW in the regulated regime, TF tends to focus more on influencing BOs directly in safeguarding customer interests, putting greater efforts into building relationships and seeking cooperation with BOs. 
TF has some functions at the tactical level, in which it advises DfT, local PTAs and BOs to take specific actions to improve their service levels. Like LTW in the regulated regime, TF mostly works at the operational level. Its main tasks (research, monitoring and controlling, and public outreach) contribute to improving the transparency of service quality levels among BOs.

Fig. 2. The passenger watchdog in the deregulated bus regime outside London (adapted from van de Velde, 1999*).

\begin{tabular}{|c|c|c|c|c|}
\hline \multirow[t]{2}{*}{ Actor } & \multicolumn{3}{|c|}{ Regulatory authority } & Operators \\
\hline & Passenger watchdog (TF) & \multicolumn{2}{|c|}{ Local PTAs } & Private $\mathrm{BOs}$ \\
\hline \multicolumn{5}{|l|}{ Relation } \\
\hline \multirow[t]{4}{*}{ Strategic } & & \multirow{3}{*}{$\begin{array}{l}\text { Correction } \\
\text { market failure }\end{array}$} & \multirow{3}{*}{ Redistribution } & General aims \\
\hline & & & & Area \\
\hline & & & & Target groups \\
\hline & & & & General service characteristic \\
\hline \multirow[t]{4}{*}{ Tactical } & & & $\begin{array}{l}\text { uthorisati } \\
\text { Rebate }\end{array}$ & $\begin{array}{r}\text { compensations } \\
\text { Fares }\end{array}$ \\
\hline & \multirow[t]{3}{*}{ Consultation } & Co-ordinating & & Routes \\
\hline & & Co-ordinating & & Timetable \\
\hline & & & Accessibility & Vehicle type \\
\hline \multirow[t]{4}{*}{ Operational } & Research & & & Sales \\
\hline & Monitor \& control & & & Information \\
\hline & \multirow[t]{2}{*}{ Public outreach } & & & Personnel \\
\hline & & & & Vehicle management \\
\hline
\end{tabular}

(*) The way how to read it as in Fig. 1 .

Our findings show that statutory passenger watchdogs can be effective in representing passengers' interests in both the regulated and deregulated bus regimes and can contribute to improving the quality of bus services. They receive cooperation from PTAs and BOs in designing and operating bus services. Four key success factors can explain this outcome: the organizational setting, research-based evidence, accommodating relationships and public outreach. Thanks to these factors, the watchdogs can draw the necessary resources to overcome the free-rider problem. They have sufficient funds to run their organizations and to mobilize participation by government, the industry and the wider public. First, being set up as an agent of the transport authorities, TF and LTW's budget is more or less guaranteed by the government. Nevertheless, the watchdogs must now 
actively seek additional funding from BOs and PTAs due to budget cutbacks. This raises questions regarding their independence and whether their behaviour might be influenced by their own selfinterest as well. These organizational arrangements also grant TF and LTW some statutory responsibilities that guarantee them certain forms of participation in decision-making processes regarding bus services, though mainly at the operational level. Second, TF and LTW are basically non-executive bodies, thus they only operate through dialogue and persuasion. To persuade PTAs and PTOs to take passengers' views into consideration, the watchdogs base their arguments on research-based evidence. In particular, operators find the national passenger survey very useful, as they use it as a guide in setting service standards (see also Andrews, 2014). Furthermore, because of their use of research-based evidence to promote bus users' interests, LTW and TF are recognized as independent watchdogs by PTAs and BOs. Third, although the watchdogs have some coercive power to get their own way, they seek for compromise solutions in their relationships with BOs and PTAs by following a strategy of accommodation. Hence, they receive support from both the government and the industry. This could be a lesson for German-speaking countries, where the relationship between passenger associations and transport companies is often tense (Dienel, 2009). Through use of research-based evidence and more accommodating relationships, the watchdogs can build their credibility and mobilize PTAs' and BOs' participation and cooperation. Fourth, the watchdogs can maintain their relevance with the wider public via public outreach by using both traditional and social media channels to encourage the public to participate in their campaigns and activities, as well as to create mass media pressure on PTAs and BOs in taking passengers' interests into consideration.

To conclude, our findings have shown that the organizational arrangements and modes of operation of British passenger watchdogs have proved to be an effective mechanism ensuring that passenger needs are considered by public transport regulators and providers. These findings, however, are based on the British case. Further comparative research on the effectiveness of different organizational arrangements (e.g. voluntary versus statutory passenger watchdogs) and of different actors (e.g. the watchdog role adopted by the PTAs versus independent, separate bodies) is needed to broaden our understandings of how passengers' interests are represented.

\section{Acknowledgements}

This research was partially funded by the Federation of German Consumer Organizations (verbraucherzentrale Bundesverband). The authors would like to thank their partners, especially 
Christoph Schaaffkamp, Lars Sturm and Paula Ruoff, at KCW GmbH in Berlin for setting up this research. Our thanks also go to Elena Nikonova and Natalia Osokina for collecting part of the data. We are grateful for the insightful comments and suggestions of the editor Greg Marsden and two anonymous reviewers.

\section{References}

Alexandersson, G., Hultén, S., 2006. Competitive tenders in passenger railway services: looking into the theory and practice of different approaches in Europe. European Transport $\backslash$ Trasporti Europei, 33, 6- 28.

Amaral, M., 2008. Public vs private management of public utilities: the case of urban public transport in Europe. Research in Transportation Economics, 22, 85- 90.

Andrews, M., 2014. National Rail Passenger Survey: - Stakeholder Review. Retrieved from: (http://d3cez36w5wymxj.cloudfront.net/migrated/NRPS\%20Stakeholder\%20Review\%20Septe $\underline{\text { mber\%202014.pdf }}$

APT (Swiss Association of Public Transport) 2016. Facts \& Figures. Swiss Public Transport 2016/2017. Retrieved from:

https://www.voev.ch/de/Service/content index.php?section=downloads\&download=2207 (accessed 2.2.2017).

Bonsall, P., 2000. Legislating for modal shift: background to the UK's new transport act. Transport Policy, 7, 179-184.

Butcher, L., 2010. Buses: deregulation in the 1980s. House of Commons - Library.

Butler, E., 2012. Public Choice: A Primer. The Institute of Economic Affairs. London.

Cass, N., Faulconbridge, J., 2016. Commuting practices: new insights into modal shift from theories of social practice. Transport Policy, 45, 1-14.

CMA (Competitive \& Markets Authority) 2016. Competition in passenger rail services in Great Britain: a policy document. Retrieved from:

(https://assets.publishing.service.gov.uk/media/56ddc41aed915d037600000d/Competition_in passenger_rail_services_in_Great_Britain.pdf) (accessed 2.9.2016). 
DfT (Department for Transport), 2014a. Annual bus statistics: England 2013/2014. Retrieved from: https://www.gov.uk/government/uploads/system/uploads/attachment_data/file/387397/annualbus-statistics-year-to-march-2014.pdf (accessed 2.9.2016).

DfT (Department for Transport), 2014b. Table BUS1001b: Operator market share of weekly bus vehicle trips by local authority: England, October 2013. Traveline National Data Set / Basemap. Retrieved from: (http://www.basemap.co.uk/data-products/public-transport$\underline{\text { data.aspx) }}$ (accessed 12.9.2016).

DfT (Department for Transport), 2014c. Management Statement for Passenger Focus (operating name for the Passengers' Council), London.

DfT (Department for Transport), 2015. Passenger Focus, Triennial Review 2014/2015. Management Statement for Passenger Focus (operating name for the Passengers' Council), London.

DfT (Department for Transport), 2016. Annual bus statistics: England 2015/2016.

Dienel, H-L., 2009. Introduction. In: Schiefelbusch, M., Dienel, H-L. (eds.), Public Transport and its Users: The Passenger's Perspective in Planning and Customer Care. Abingdon: Ashgate Publications, pp. 1-3.

Elgin, D.S., Bushnell, R. A., 1977. The limits to complexity: are bureaucracies becoming unmanageable? The Futurist, (December), pp. 327-349.

Flyvbjerg, B., 2006. Five misunderstandings about case-study research. Qualitative Inquiry 12 (2), $219-245$.

Go-Ahead, 2016. Annual report and accounts 2016, pp. 18-22.

Guest, J., 2015. Preface. In Brobeck, S., Mayer, S. R. (eds.), Watchdogs and Whistleblowers: A Reference Guide to Consumer Activism. Santa Barbara, CA: ABC-CLIO, pp. vii-viii.

Hansson, L., 2010. Solving procurement problems in public transport: examining multi-principal roles in relation to effective control mechanisms. Research in Transportation Economics, 29, $121-132$.

Hensher, D.A., Wong, G., 2011. Different Approaches to Public Transport Provision. Journeys, 7, $31-41$. 
Jansen, H., Schiefelbusch, M., 2009. Chapter 4.6.1. User Associations: Common Features and Experiences. In: Schiefelbusch, M., Dienel, H-L. (Eds.), Public Transport and its Users: The Passenger's Perspective in Planning and Customer Care. Abingdon: Ashgate Publications, pp. $154-165$.

London Assembly (2010). Review of London TravelWatch. London: Greater London Authority. Retrieved from:

(https://www.london.gov.uk/sites/default/files/gla migrate files destination/Review-LondonTravelWatchPDF_0.pdf) (accessed 3.02. 2016).

LTW (London TravelWatch), 2015a. London TravelWatch Presentation 2015.

LTW (London TravelWatch), 2015b. Annual Review 2015. Retrieved from:

(http://www.londontravelwatch.org.uk/documents/get_lob?id=4017\&field=file) (accessed 28.10. 2015).

Lyons, G., Harman, R., 2002. The UK public transport industry and provision of multi-modal traveller information. International Journal of Transport Management, 1, 1-13.

Marcucci, E., 2002. The Process of Railway De-Verticalisation in Italy: State of the Art and Possible Evolutions. European Transport $\backslash$ Trasporti Europei 20-21, 25-33.

Matthews, B., Bristow, A., Nash, C., 2001. Competitive tendering and deregulation in the British bus market: a comparison of impacts on costs and demand in London and the British Metropolitan Areas. Paper presented at THREDBO7 2001: Molde, Norway. Retrieved from: (http://www.thredbo-conference-series.org/downloads/thredbo7 papers/thredbo7-workshopAMatthews-Bristow-Nash.pdf) (accessed 3.4.2016).

Mokonyama, M., Venter, C., 2013. Incorporation of customer satisfaction in public transport contracts: a preliminary analysis. Research in Transportation Economics, 39(1), 56-66

Nash, C., Matthews, B., 2002. Implementing Marginal Cost Pricing of Rail Infrastructure-Barriers and Solutions. European Transport \Trasporti Europei 20-21, 16-24.

Olson, M., 1965. The Logic of Collective Action: Public Goods and the Theory of Groups. Cambridge MA: Harvard University Press. 
Oonagh, G., Winetrobe, B. K., 2008. Chapter 1: Introduction. Watchdogs in Need of Support. In: Oonagh, G., Winetrobe, B. K. (eds.), Parliament's Watchdogs: At The Crossroads. The Constitution Unit, pp. 11-16.

Passenger Focus, 2012. Bus Passenger Survey on Go-Ahead's bus passengers outside the London area. Headline results for each: Go-Ahead bus company. Retrieved from: (https://transportfocus.s3-eu-west-1.amazonaws.com/migrated/GoAhead $\% 20$ Bus $\% 20$ Passenger $\% 20$ Survey $\% 20$ Report $\% 20-\% 20$ September $\% 202012 \% 20$ \%20Go-Ahead $\% 20$ overall\%20group \%20results.pdf.) (Accessed 5.9.2016).

Ponti, M., Erba, S., 2002. Railway Liberalization from a "Public Choice" Perspective. European Transport $\backslash$ Trasporti Europei 20-21, 38-46.

Preston, J., 1991. Explaining competitive practices in the bus industry: the British experience. Transportation Planning and Technology, 15(2-4), 277-294.

Preston, J., Almutairi, T., 2013. Evaluating the long term impacts of transport policy: an initial assessment of bus deregulation. Research in Transportation Economics, 39, 208-214.

Schaaffkamp, C., 2014. How can customer focus be strengthened in competitive tendering? Research in Transportation Economics, 48, 305-314.

Schiefelbusch, M., 2005. Citizens' Involvement and the Representation of Passenger Interests in Public Transport: Dimensions of a Long-neglected Area of Transport Planning and Policy with Case Studies from Germany. Transport Reviews, 25(3), 261-282.

Schiefelbusch, M., Böhme, U., Faas, H-P., 2009. Chapter 3.4. Users and User Organisations in Quality Management. In: Schiefelbusch, M., Dienel, H-L. (eds.), Public Transport and its Users: The Passenger's Perspective in Planning and Customer Care. Abingdon: Ashgate Publications, pp. 98-113.

TF (Transport Focus), 2016a. Bus Passenger Survey: Full Report, Autumn 2015. Retrieved from: (http://www.transportfocus.org.uk/research-publications/publications/bus-passenger-surveyfull-report-autumn-2015/) (accessed 20.03.2016).

TF (Transport Focus), 2016b. Bus Passengers have their Say: Trust, what to improve and using buses more. Retrieved from: 
(http://d3cez36w5wymxj.cloudfront.net/migrated/Bus\%20passengers\%20have\%20their\%20say \%20-\%20MARCH\%202016\%20FINAL.pdf) (accessed 15.12.2016).

TF (Transport Focus), n.d. History. Retrieved from:

(http://www.transportfocus.org.uk/about/history) (accessed 2.02.2016).

TfL (Transport for London), n.d. What we do. Retrieved from: (https://tfl.gov.uk/corporate/about-

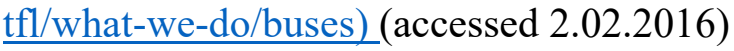

TfL (Transport for London), 2015. London's Bus Contracting and Tendering Process. Retrieved from: (http://content.tfl.gov.uk/uploads/forms/lbsl-tendering-and-contracting.pdf) (accessed 3.02.2016).

Transport Act, 1947. Public general acts and the church assembly, 10 and 11 Geo VI, C.49. HMSO, London.

van de Velde, D., Preston, J., 2013. Workshop 3B: Governance, ownership and competition issues in deregulated (free market) public transport: lessons that can be learnt from developed and developing economies. Research in Transportation Economics, 39(1), 202-207.

van de Velde, D., 1999. Organisational forms and entrepreneurship in public transport, part 1: classifying organisational forms. Transport Policy, 6, 147-157.

VOSA (Vehicle \& Operator Services Agency), 2011. Public Service Vehicle Operator Licensing: Guide for Operators.

White Paper, 2004. The Future of Rail. The Stationery Office, Norwich.

White, P., 2010. Review of Public Transport and its Users: The Passenger's Perspective in Planning and Customer Care. Transport Reviews, 30(6), 805-806.

White, P. R., 2010. The conflict between competition policy and the wider role of the local bus industry in Britain. Research in Transportation Economics, 29(1), 152-158.

Wright, I., Bailey, K., Minshull, H., 2015. National Rail Passenger Survey (NRPS): Consultation Feedback Report. Transport Focus. London. 